The Bangladesh Veterinarian (2011) 28(1): $1-7$

\title{
Peste des petits ruminants virus infection of goats in Bangladesh: Pathological investigation, molecular detection and isolation of the virus
}

\author{
M. A. Rahman, I. Shadmin, M. Noor, R. Parvin, E. H. Chowdhury and \\ M. R. Islam* \\ Department of Pathology, Faculty of Veterinary Science, Bangladesh Agricultural \\ University, Mymensingh-2202, Bangladesh
}

\begin{abstract}
Peste des petits ruminants (PPR), an economically important morbillivirus infection of sheep and goats, is widely distributed in sub-Saharan Africa, Middle East and western and southern Asia including Bangladesh. A small flock of Black Bengal goats contracted PPR following introduction of new animals. A pathological investigation was conducted on the outbreak, the viral RNA corresponding to F gene was detected by RT-PCR and the virus was isolated in Vero cells. Out of 37 goats 19 (51\%) developed clinical disease, of which $5(13.5 \%)$ died. Goats under one year of age had highest morbidity and mortality with typical signs and lesions of PPR. Viral RNA could be detected in mesenteric and bronchial lymph node tissues. Typical cytopathic effects (CPE) in Vero cells following inoculation of lymph node tissue homogenate were visible at the third passage. However, the replication of virus in cell culture was detected by RT-PCR at the first and second passage in the absence of visible CPE. RT-PCR appears to be a very useful and sensitive tool not only for the detection of PPR virus in clinical samples but also for monitoring the growth of virus in cell culture following inoculation. (Bangl. vet. 2011. Vol. 28, No. 1, 1-7)
\end{abstract}

\section{Introduction}

Peste des petits ruminants (PPR) are a highly contagious and economically important viral disease of domestic and wild small ruminants. The disease is caused by a morbillivirus under the family Paramyxoviridae (Gibbs et al., 1979; Bailey et al., 2005). Clinically, PPR resembles rinderpest and is characterized by the sudden onset of depression, fever, discharges from the eyes and nose, sores in the mouth, disturbed breathing and cough, foul-smelling diarrhoea, with 100\% morbidity and 20-90\% mortality (EMPRES, 1999). Pseudomembranous, erosive, and ulcerative stomatitis; necrotic tonsillitis; fibrino-haemorrhagic enteritis; and broncho-interstitial pneumonia are the major pathological features (Rowland et al., 1969; Bundza et al., 1988; Brown al., 1991; Kul et al., 2007). PPR was first described in Côte d'Ivoire in West Africa in 1942. The disease is now widespread in tropical and sub-tropical countries, particularly in sub-Saharan Africa, Middle East and western and southern Asia (Dhar et al., 2002). In Bangladesh, PPR is considered to be prevalent in goats since 1993 (Islam et al., 2001). The present paper reports an investigation of a PPR outbreak in a

*Corresponding author:- E-mail: mrislam_bau@yahoo.com 
goat flock in Bangladesh, including pathological observations, molecular detection and isolation of the virus.

\section{Materials and Methods}

The study was conducted on a natural outbreak of the disease in July 2007 in a flock of 37 Black Bengal goats raised by the Department of Animal Breeding and Genetics of Bangladesh Agricultural University, Mymensingh for experimental purposes. Detailed history and clinical features of the outbreak recorded.

\section{Pathological investigation}

Routine necropsy was performed on dead goats. Gross pathological changes were recorded. The samples of trachea, lung, spleen, lymph node, rumen, intestine, kidney, heart and liver containing lesions were collected for histopathological study and fixed in $10 \%$ neutral buffered formalin. Pieces of mesenteric and bronchial lymph nodes were collected aseptically and stored at $-70^{\circ} \mathrm{C}$ for molecular detection and isolation of the virus. Formalin-fixed tissues were processed for paraffin embedding, sectioned and stained with haematoxylin and eosin for histopathological study following standard procedures (Luna, 1968).

\section{Molecular detection of the virus}

A reverse transcription polymerase chain reaction (RT-PCR) was adopted for the detection of PPR virus. The reaction was carried out with a PPRV-specific primer set (PPRVF1b: 5'-AGT ACA AAA GAT TGC TGA TCA CAG T-3' and PPRVF2d: 5'-GGG TCT CGA AGG CTA GGC CCG AAT A-3') originally designed by Forsyth and Barrett (1995) to amplify a 448-bp cDNA product from the $\mathrm{F}$ gene spanning from the nucleotide position 760 to 1207 . A lyophilized live PPR vaccine, produced by the Livestock Research Institute (LRI), Mohakhali, Dhaka, Bangladesh, was used as the positive control. RNA was extracted from the reconstituted vaccine or tissue homogenate from the field samples using RNeasy Mini Kit (Qiagen, Germany) according to manufacturer's protocol. The RT-PCR was performed with Qiagen OneStep RT-PCR kit (Qiagen, Germany). The thermocycling profile was as follows: reverse transcription at $50^{\circ} \mathrm{C}$ for $30 \mathrm{~min}$, initial denaturation and activation of polymerase at $94^{\circ} \mathrm{C}$ for $15 \mathrm{~min}$, followed by 35 cycles of denaturation, annealing and extension at $94^{\circ} \mathrm{C}$ for $1 \mathrm{~min}, 50^{\circ} \mathrm{C}$ for $1 \mathrm{~min}$ and $72^{\circ} \mathrm{C}$ for $2 \mathrm{~min}$, respectively, and final elongation at $72^{\circ} \mathrm{C}$ for $7 \mathrm{~min}$. The RT-PCR products were analysed by electrophoresis on $1.5 \%$ agarose gel stained with ethidium bromide.

\section{Isolation of the virus}

PPR virus was isolated in Vero cells from mesenteric and bronchial lymph node tissues of affected animals. The lymph nodes were macerated with sterile mortar and pestle to prepare a $20 \%(\mathrm{w} / \mathrm{v})$ tissue homogenate in Dulbecco's phosphate buffered saline (PBS)-A. The suspension was clarified by centrifugation $(800 \mathrm{~g})$ for $10 \mathrm{~min}$, the supernatant was collected in fresh Falcon tube and treated with gentamycin 500 
$\mu \mathrm{g} / \mathrm{ml}$ for $30 \mathrm{~min}$ at room temperature. The treated suspension was stored in aliquots at $-70^{\circ} \mathrm{C}$ until used. Prior to use, the suspension was passed through a syringe filter of $0.2 \mu \mathrm{m}$ pore size and the filtrate was used as the inoculum.

Confluent monolayers of Vero cells were prepared in $25 \mathrm{sq} \mathrm{cm}$ flasks following standard subculture procedure (Freshney, 2003) using Dulbecco's modified Eagle's medium (MEM) enriched with 5\% fetal calf serum. For isolation of the virus $200 \mu \mathrm{l}$ of each sample was inoculated in duplicate flasks. The cells were examined daily for cytopathic effects (CPE). Each sample was subjected to three blind passages irrespective of the appearance of CPE. After each passage the cell culture supernatant was tested by RT-PCR for the detection of PPR virus as described above.

\section{Results and Discussion}

Epidemiological features of the outbreak

The present PPR outbreak occurred in a small flock of goats in July, 2007, the rainy season. Out of 37 goats 19 (51\%) developed clinical disease, and 5 (13.5\%) died. Age distribution of morbidity and mortality is shown in Table 1.

Table 1. Age distribution of morbidity and mortality due to PPR in a small flock of goats

\begin{tabular}{l|c|c|c}
\hline \multicolumn{1}{c|}{ Age groups } & No. of flocks & No. affected & No. died \\
\hline 0-4 months & 8 & 7 & 3 \\
5-8 months & 9 & 9 & 2 \\
9-12 months & 5 & 2 & - \\
13-24 months & 12 & 1 & - \\
$>$ 24 months & 3 & - & - \\
\hline
\end{tabular}

Goats under one year of age had highest morbidity and mortality. In endemic situation it is expected that very young kids would be protected by maternal antibodies. It has been observed, however, that although PPR is widespread in Bangladesh, seroprevalence varied from region to region (6 to $49 \%$ ); only $12.5 \%$ goats were seropositive in Mymensingh region (E. H. Chowdhury, unpublished). It is very likely that young kids of the flock under study were born to non-immune does. The immune status of the older goats is not known.

Of the 19 affected goats 8 had recently been purchased from a local market. Immediately before this outbreak, goats in the neighbouring villages were affected by a disease with similar signs. Animal movement, particularly introduction of new animals into a flock, is considered an epidemiologically significant event in the spread of PPR (EMPRES, 1999).

\section{Clinical and pathological findings}

The clinical signs included fever (up to $107^{\circ} \mathrm{F}$ ), depression, anorexia, serous to 
mucopurulent nasal discharge, severe dehydration, erosions and ulcerations in the buccal cavity, diarrhoea and respiratory distress. Frothy salivation and conjunctivitis were also found.

At necropsy, stomatitis with erosions, ulcerations and necrotic lesions in the buccal cavity, erosions on the pillars of rumen, severe congestion throughout the intestinal tract, zebra stripes in caeco-colic junction, and pale and moderately enlarged liver with distended gall bladder were the main gross lesions in the digestive system. Congested and consolidated lungs, enlarged and oedematous lymph nodes, paintbrush haemorrhages in the heart and atrophied spleen were found.

Histologically, non-purulent enteritis with congestion and infiltration of large mononuclear cells in the lamina propria and loss of lining epithelium were seen in the intestine. Loss of surface epithelium and congestion were seen in the rumen. Sloughing of surface epithelium and infiltration of mononuclear cells were in the trachea. In the lung, inflammatory exudates containing large amounts of fibrin accumulated over a considerable area of the parenchyma, the alveoli and interstitium were severely infiltrated with reactive cells, predominantly mononuclear cells (Fig. 1). Depletion of lymphocytes and infiltration of macrophages were in lymph nodes. The clinical and pathological features were similar to those described elsewhere (Rowland et al., 1969, Bundza et al., 1988; Brown et al., 1991; EMPRES, 1999; Islam et al., 2001; Kul et al., 2007).

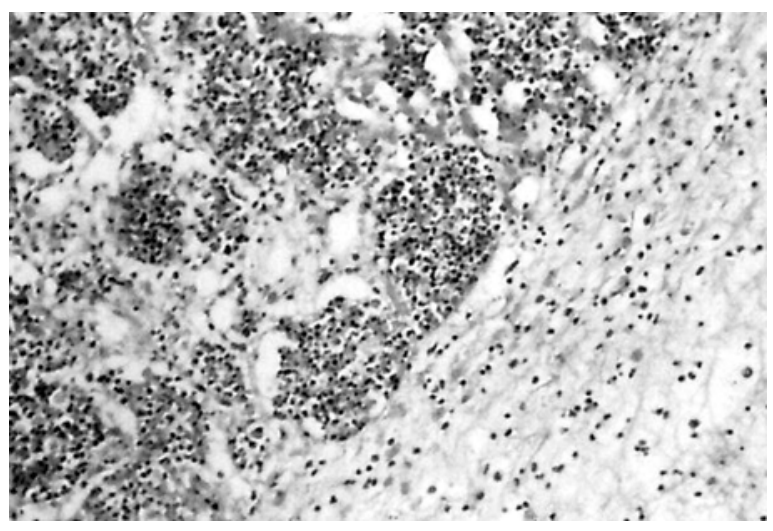

Fig. 1. Section of the lung of a goat that died of PPR, showing accumulation of exudates containing fibrin and many inflammatory cells. (H\&E stain, 10x objective)

Molecular detection of the virus by RT-PCR

An RT-PCR method was successfully adopted to amplify a fragment of F gene of PPR virus. RNA extracted from a vaccine strain of PPR virus was used as the template for standardization of the test protocol. A $448 \mathrm{bp}$ fragment of F gene was amplified (Fig. 2). The test was then successfully applied to detect PPR viral RNA in lymph node tissues of two selected field samples and both were positive. The RT-PCR 
method, applied for the first time in Bangladesh, was a convenient tool for detection of PPR virus directly from clinical samples.

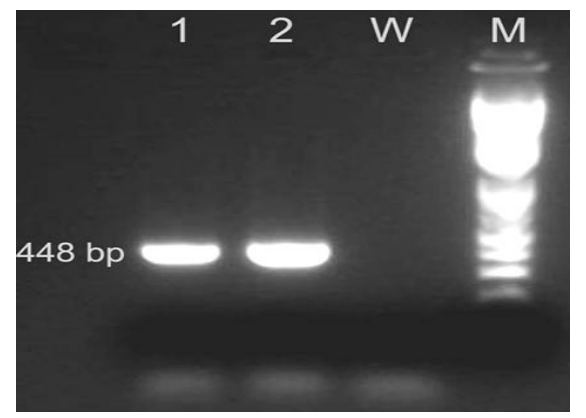

Fig. 2. Amplification of $448 \mathrm{bp}$ fragment of $\mathrm{F}$ gene of a PPR vaccine virus by RT-PCR. $(1.5 \%$ agarose stained with ethidium bromide, $\mathrm{M}=$ Marker, $\mathrm{W}=$ Water (negative) control, 1 \& 2 = PPR vaccine virus)

Virus isolation in cell culture and identification by RT-PCR

Following inoculation of Vero cells with filtered homogenate of lymph node tissues no detectable CPE was observed during the first two passages. However, on the third passage $\mathrm{CPE}$, characterized by rounding and aggregation of cells, was noticed 32 hours after inoculation. Grape-like clusters and small syncytia were observed 5 days after inoculation.

The original inoculum and the tissue culture supernatants collected at each passage were tested by RT-PCR. Viral RNA could be detected by RT-PCR at each passage (Fig. 3). As judged from the intensity of the band in agarose gel, the concentration of RT-PCR amplicon gradually increased with the number of passages.

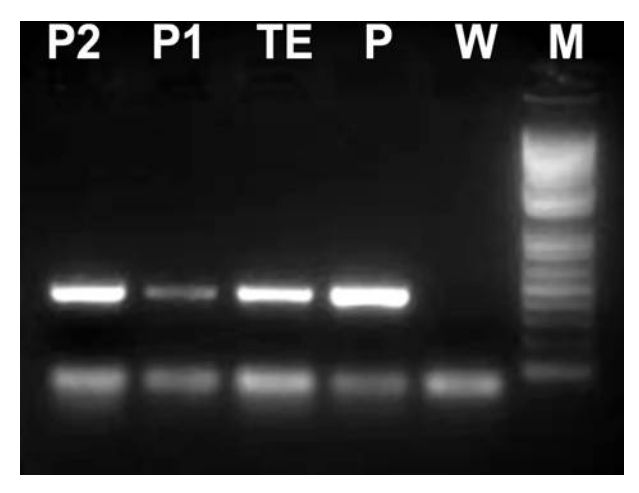

Fig. 3. Amplification of $448 \mathrm{bp}$ fragment of $\mathrm{F}$ gene of PPR virus by RT-PCR from the original tissue sample and inoculated Vero cell culture supernatant. (1.5\% agarose stained with ethidium bromide, $\mathrm{M}=$ Marker, $\mathrm{W}=$ Water (negative) control, $\mathrm{P}=$ Positive control ( $\mathrm{PPR}$ vaccine virus), $\mathrm{T}=$ Lymph node tissue homogenate of an infected goat, P1 = Cell culture supernatant, first passage, P2 = Cell culture supernatant, second passage) 
Classically, the growth of PPR virus in cell culture is confirmed by virus neutralization test with known antiserum. In the present study, RT-PCR was employed to ascertain the growth of PPR virus in cell culture. This technique could detect the virus in cell culture supernatant before the appearance of visible CPE. Although the positive RT-PCR result after the first passage could be due to the residual inoculum, an increased concentration of the RT-PCR products in the second passage, yet in the absence of visible CPE, would confirm active replication of the virus in cell culture. The concentration of RT-PCR products further increased after the third passage when virus-induced CPE was also obvious. Hence, RT-PCR can be used not only for the detection of PPR virus in clinical samples but also for monitoring the growth of virus in cell culture following inoculation.

\section{References}

Bailey D, Banyard A, Dash P, Ozkul A and Barrett T 2005: Full genome sequence of peste des petits ruminants virus, a member of the Morbillivirus genus. Virus Research 110 119-124.

Brown CC, Mariner JC and Olander HJ 1991: An immunohistochemical study of pneumonia caused by peste des petits ruminants virus. Veterinary Pathology 28 166-170.

Bundza A, Afshar A, Dukes TW, Mayers DJ, Dulac GC and Becker SAWE 1988: Experimental peste des petits ruminants (goat plague) in goats and sheep. Canadian Journal of Veterinary Research 52 46-52.

Dhar P, Sreenivasa BP, Barrett T, Corteyn M, Singh RP, Bandyopadhyay SK 2002: Recent epidemiology of peste des petits ruminants virus (PPRV). Veterinary Microbiology 88 153-159.

EMPRES 1999: Recognizing Peste des Petits Ruminants. Food and Agriculture Organisation of the United Nations, Rome. 28 pp.

Forsyth MA and Barrett T 1995: Evaluation of polymerase chain reaction for the detection and characterisation of rinderpest and peste des petits ruminants viruses for epidemiological studies. Virus Research 39 151-163.

Freshney RI 1983: Culture of Animal Cells: A Manual of Basic Technique, $3^{\text {rd }}$ ed. John Wiley \& Sons Canada. 310 pp.

Gibbs EPJ, Taylor WP, Lawman MJP and Bryant J 1979: Classification of peste des petits ruminants virus as the fourth member of the genus Morvillivirus. Intervirology 11 268-274.

Islam MR, Shamsuddin M, Rahman MA, Das PM and Dewan ML 2001: An outbreak of peste des petits ruminants in Black Bengal goats in Mymensingh, Bangladesh. The Bangladesh Veterinarian 18 14-19. 
Kul O, Kabakci N, Atmaca HT and Özkul A 2007: Natural peste des petits ruminants virus infection: novel pathologic findings resembling other Morbillivirus infections. Veterinary Pathology 44 479-486.

Luna LG (Ed.) 1968: Manual of Histologic Staining Methods of the Armed Forces Institute of Pathology. Armed Forces Institute of Pathology, Huoston, USA pp. 258.

Rowland AC, Scott GR and Hill DH 1969: The pathology of an erosive stomatitis and enteritis in West African dwarf goats. Journal of Pathology 98 83-87. 